\title{
Appropriateness of Outpatient Antibiotic Use in Seniors across Two Canadian Provinces
}

\author{
Ariana Saatchi ${ }^{1}$, Jennifer N. Reid ${ }^{2,3}$, Marcus Povitz ${ }^{4}$, Salimah Z. Shariff ${ }^{2,3}$, Michael Silverman ${ }^{3,5}$, \\ Andrew M. Morris ${ }^{6}$, Romina C. Reyes ${ }^{7}$, David M. Patrick ${ }^{8,9}$ and Fawziah Marra ${ }^{1,8, *}$
}

1 Faculty of Pharmaceutical Sciences, University of British Columbia, Vancouver, BC V6T 1Z4, Canada; ariana.saatchi@ubc.ca

2 Institute for Clinical Evaluative Sciences, London, ON N6A 5W9, Canada; jennifer.reid@ices.ca (J.N.R.); salimah.shariff@ices.on.ca (S.Z.S.)

3 Lawson Health Research Institute, London, ON N6C 2R5, Canada; michael.silverman@sjhc.london.on.ca

4 Department of Medicine, University of Calgary, Calgary, AB T2N 1N4, Canada; marcuspovitz@gmail.com

5 Faculty of Medicine, Division of Infectious Diseases, University of Western Ontario, London, ON N6A 3K7, Canada

6 Department of Medicine, Sinai Health, University Health Network, University of Toronto, Toronto, ON N6A 3K7, Canada; andrew.morris@sinaihealthsystem.ca

7 LifeLabs, Vancouver, BC V5Z 1H6, Canada; romina.reyes@lifelabs.com

8 British Columbia Centre for Disease Control, Vancouver, BC V5Z 4R4, Canada; david.patrick@bccdc.ca

9 School of Population and Public Health, University of British Columbia, Vancouver, BC V6T 1Z4, Canada

* Correspondence: fawziah@mail.ubc.ca; Tel.: +1-604-822-7898

Citation: Saatchi, A.; Reid, J.N.; Povitz, M.; Shariff, S.Z.; Silverman, M.; Morris, A.M.; Reyes, R.C.; Patrick, D.M.; Marra, F. Appropriateness of Outpatient Antibiotic Use in Seniors across Two Canadian Provinces. Antibiotics 2021, 10, 1484. https:// doi.org/10.3390/antibiotics10121484

Academic Editor: Raymond J. Turner

Received: 15 November 2021

Accepted: 2 December 2021

Published: 3 December 2021

Publisher's Note: MDPI stays neutral with regard to jurisdictional claims in published maps and institutional affiliations.

Copyright: (c) 2021 by the authors. Licensee MDPI, Basel, Switzerland. This article is an open access article distributed under the terms and conditions of the Creative Commons Attribution (CC BY) license (https:// creativecommons.org/licenses/by/ $4.0 /)$.
Abstract: Antimicrobials are among the most prescribed medications in Canada, with over 90\% of antibiotics prescribed in outpatient settings. Seniors prescribed antimicrobials are particularly vulnerable to adverse drug events and antimicrobial resistance. The extent of inappropriate antibiotic prescribing in outpatient Canadian medical practice, and the potential long-term trends in this practice, are unknown. This study is the first in Canada to examine prescribing quality across two large-scale provincial healthcare systems to compare both quantity and quality of outpatient antibiotic use in seniors. Population-based analyses using administrative health databases were conducted in British Columbia $(\mathrm{BC})$ and Ontario $(\mathrm{ON})$, and all outpatient, oral antimicrobials dispensed to seniors ( $\geq 65$ years) from 1 January 2000 to 31 December 2018 were identified. Antimicrobials were linked to an indication using a 3-tiered hierarchy. Tier 1 indications, which always require antibiotics, were given priority, followed by Tier 2 indications that sometimes require antibiotics, then Tier 3 , which never require antibiotics. Prescription rates were calculated per 1000 population, and trends were examined overall, by drug class, and by patient demographics. Prescribing remained steady in both provinces, with 11,166,401 prescriptions dispensed overall in BC, and 27,656,014 overall in ON. BC prescribed at slightly elevated rates (range: 790 to 930 per 1000 residents), in comparison to ON (range: 745 to 785 per 1000 residents), throughout the study period. For both provinces, a Tier 3 diagnosis was the most common reason for antibiotic use, accounting for $50 \%$ of all indication-associated antibiotic prescribing. Although Tier 3 indications remained the most prescribed-for diagnoses throughout the study period, a declining trend over time is encouraging, with much room for improvement remaining. Elevated prescribing to seniors continues across Canadian outpatient settings, and prescribing quality is of high concern, with $50 \%$ of all antimicrobials prescribed inappropriately for common infections that do not require antimicrobials.

Keywords: antibiotics; antimicrobial drug resistance; outpatient care; inappropriate prescribing

\section{Introduction}

The World Health Organization formally acknowledged the crisis of antimicrobial resistance (AMR) in 2014, and released a global action plan the next year [1]. In response, the United States, the United Kingdom (UK) and Australia have not only established 
jurisdiction-specific plans for the reduction of antibiotic use, but have also gone one step further and pledged to decrease inappropriate antibiotic use [2-5]. Despite the urgency, Canada has yet to disseminate a national action plan that focuses on the quality of antibiotic prescribing [6]. The continued knowledge gap on suboptimal prescribing quality precludes the scope of tangible targets for intervention, and research to parse inappropriate antibiotic use in Canada is vital $[7,8]$.

Outpatient prescribing accounts for the majority of human antibiotic use in Canada, with $90 \%$ of all antibiotics dispensed in the community setting [8]. Evaluating appropriate antibiotic use is especially relevant for older Canadians ( $\geq 65$ years), who are prescribed antimicrobials at elevated rates compared to other cohorts, particularly for respiratory tract infections (RTI) and urinary tract infections (UTI), with incidence of hospitalizations and "superbug" infections greater than in younger populations [9-14]. Historically, antibiotic use in seniors has been framed as a catch-22 situation, wherein both the prescription and/or reservation of antibiotics confer increased patient risk for adverse outcomes; however, recent studies counter this myth and report no association between reductions in antibiotic use and increased bacterial complications [15]. In the absence of documented patient harms, the stagnant rates of prescribing in Canadian seniors are especially alarming and require prompt attention to reduce antibiotic use within this population. In Canada, antibiotic receipt is the single most important risk factor for Clostridioides difficile infection and the acquisition of resistant infections, and it is the second most common cause of emergency department visits for adverse drug events [16,17]. Despite moderate declines in incidence across Canada since 2009, C. difficile remains one of the most burdensome pathogens, particularly in the elderly, causing more deaths than influenza each year [16].

On a global scale, the quantities of antibiotic use in humans, animals and agriculture have been surveilled for decades [18-21]. However, studies examining prescription quality have been hindered by the absence of encompassing guidelines, varying clinical factors and a high-level of expert subjectivity in defining inappropriate use. Moreover, the defining features of inappropriate use-antibiotic prescription in the absence of a bacterial etiology, the overuse of broad-spectrum agents, suboptimal dosing and/or duration of therapy-are diverse and difficult to aggregate [22]. Spivak et al. characterized early attempts to measure prescribing quality as trying to open a black box [22]. Since the publication of Spivak's paper, several countries, including the United States and the UK have published criteria that define appropriateness; however, in Canada, inappropriate antibiotic use has remained largely unexamined and unknown. This study is the first in Canada to examine prescribing quality across two large-scale provincial healthcare systems to compare both quantity and quality of outpatient antibiotic prescription. Our objective was to evaluate trends of use over time in order to identify specific targets for subsequent intervention in a high-risk population.

\section{Results}

An average of 736,750 unique patients in Ontario (ON), and 587,705 in British Columbia (BC), were prescribed an antibiotic in any study year, with roughly 39 million total antibiotic prescriptions dispensed over the 19-year period (Table 1). The mean annual age of our cohort was 76 years in BC (SD: 8.3) and 75 years in ON (SD: 7.9). On average, about $38 \%$ of BC seniors were dispensed antibiotics in any study year, with $39 \%$ of ON seniors receiving prescriptions. 
Table 1. Cohort Characteristics.

\begin{tabular}{|c|c|c|c|c|c|c|c|c|}
\hline \multirow{2}{*}{$\begin{array}{l}\text { Cohort Characteristics } \\
(N)\end{array}$} & \multicolumn{4}{|c|}{ British Columbia } & \multicolumn{4}{|c|}{ Ontario } \\
\hline & Overall & 2000 & 2009 & 2018 & Overall & 2000 & 2009 & 2018 \\
\hline Total Unique Patients & $4,858,511$ & 201,610 & 244,228 & 319,057 & $13,998,138$ & 601,759 & 703,900 & 946,499 \\
\hline \multicolumn{9}{|l|}{$\begin{array}{l}\text { Number of patients by age } \\
\qquad(\%)\end{array}$} \\
\hline $65-79$ & $\begin{array}{c}3,389,791 \\
(69.8 \%)\end{array}$ & $\begin{array}{l}146,173 \\
(72.5 \%)\end{array}$ & $\begin{array}{l}167,001 \\
(68.4 \%)\end{array}$ & $\begin{array}{l}227,559 \\
(71.3 \%)\end{array}$ & $\begin{array}{c}9,980,422 \\
(71.3 \%)\end{array}$ & $\begin{array}{l}456,569 \\
(75.9 \%)\end{array}$ & $\begin{array}{l}494,359 \\
(70.2 \%)\end{array}$ & $\begin{array}{l}674,699 \\
(71.3 \%)\end{array}$ \\
\hline $80+$ & $\begin{array}{c}1,468,720 \\
(30.2 \%)\end{array}$ & $\begin{array}{l}55,437 \\
(27.5 \%)\end{array}$ & $\begin{array}{l}77,227 \\
(31.6 \%)\end{array}$ & $\begin{array}{l}91,498 \\
(28.7 \%)\end{array}$ & $\begin{array}{c}4,017,836 \\
(28.7 \%)\end{array}$ & $\begin{array}{l}145,190 \\
(24.1 \%)\end{array}$ & $\begin{array}{l}209,541 \\
(29.8 \%)\end{array}$ & $\begin{array}{l}271,800 \\
(28.7 \%)\end{array}$ \\
\hline \multicolumn{9}{|l|}{$\begin{array}{l}\text { Number of patients by sex } \\
\qquad(\%)\end{array}$} \\
\hline Female & $\begin{array}{c}2,752,378 \\
(56.7 \%)\end{array}$ & $\begin{array}{l}114,265 \\
(56.7 \%)\end{array}$ & $\begin{array}{l}138,883 \\
(56.9 \%)\end{array}$ & $\begin{array}{l}178,936 \\
(56.1 \%)\end{array}$ & $\begin{array}{c}8,189,152 \\
(58.5 \%)\end{array}$ & $\begin{array}{l}355,282 \\
(59.0 \%) \\
\end{array}$ & $\begin{array}{l}413,658 \\
(58.8 \%) \\
\end{array}$ & $\begin{array}{l}545,627 \\
(57.6 \%) \\
\end{array}$ \\
\hline Male & $\begin{array}{c}2,103,436 \\
(43.3 \%)\end{array}$ & $\begin{array}{c}86,900 \\
(43.1 \%)\end{array}$ & $\begin{array}{l}105,257 \\
(43.1 \%)\end{array}$ & $\begin{array}{l}140,115 \\
(43.9 \%)\end{array}$ & $\begin{array}{c}5,809,106 \\
(41.5 \%)\end{array}$ & $\begin{array}{l}246,477 \\
(41.0 \%)\end{array}$ & $\begin{array}{l}290,242 \\
(41.2 \%)\end{array}$ & $\begin{array}{l}400,872 \\
(42.4 \%)\end{array}$ \\
\hline \multicolumn{9}{|l|}{$\begin{array}{l}\text { Number of patients by } \\
\text { income quintile }^{1}(\%)\end{array}$} \\
\hline Quintile $^{2} 1$ (Lowest) & $\begin{array}{c}1,031,509 \\
(21.2 \%)\end{array}$ & $\begin{array}{c}47,707 \\
(23.7 \%) \\
\end{array}$ & $\begin{array}{c}52,032 \\
(21.3 \%)\end{array}$ & $\begin{array}{c}64,684 \\
(20.3 \%) \\
\end{array}$ & $\begin{array}{c}2,813,645 \\
(20.1 \%)\end{array}$ & $\begin{array}{l}128,790 \\
(21.4 \%) \\
\end{array}$ & $\begin{array}{l}135,953 \\
(19.3 \%) \\
\end{array}$ & $\begin{array}{l}192,716 \\
(20.4 \%) \\
\end{array}$ \\
\hline Quintile 2 & $\begin{array}{l}979,783 \\
(20.2 \%) \\
\end{array}$ & $\begin{array}{l}39,759 \\
(19.7 \%) \\
\end{array}$ & $\begin{array}{c}50,011 \\
(20.5 \%) \\
\end{array}$ & $\begin{array}{c}63,912 \\
(20.0 \%) \\
\end{array}$ & $\begin{array}{c}2,938,637 \\
(21.0 \%) \\
\end{array}$ & $\begin{array}{l}133,887 \\
(22.2 \%)\end{array}$ & $\begin{array}{l}144,402 \\
(20.5 \%) \\
\end{array}$ & $\begin{array}{l}198,441 \\
(21.0 \%)\end{array}$ \\
\hline Quintile 3 & $\begin{array}{l}920,488 \\
(19.0 \%)\end{array}$ & $\begin{array}{c}36,471 \\
(18.1 \%)\end{array}$ & $\begin{array}{l}46,374 \\
(19 \%) \\
\end{array}$ & $\begin{array}{c}61,574 \\
(19.3 \%)\end{array}$ & $\begin{array}{c}2,772,633 \\
(19.8 \%)\end{array}$ & $\begin{array}{l}120,285 \\
(20.0 \%)\end{array}$ & $\begin{array}{l}138,695 \\
(19.7 \%)\end{array}$ & $\begin{array}{l}188,395 \\
(19.9 \%)\end{array}$ \\
\hline Quintile 4 & $\begin{array}{l}888,518 \\
(18.3 \%) \\
\end{array}$ & $\begin{array}{l}33,419 \\
(16.6 \%) \\
\end{array}$ & $\begin{array}{c}44,544 \\
(18.2 \%) \\
\end{array}$ & $\begin{array}{c}61,254 \\
(19.2 \%) \\
\end{array}$ & $\begin{array}{c}2,670,403 \\
(19.1 \%)\end{array}$ & $\begin{array}{l}105,682 \\
(17.6 \%) \\
\end{array}$ & $\begin{array}{l}140,380 \\
(19.9 \%) \\
\end{array}$ & $\begin{array}{l}177,228 \\
(18.7 \%) \\
\end{array}$ \\
\hline Quintile 5 (Highest) & $\begin{array}{l}949,983 \\
(19.6 \%) \\
\end{array}$ & $\begin{array}{c}36,246 \\
(18.0 \%) \\
\end{array}$ & $\begin{array}{c}47,952 \\
(19.6 \%) \\
\end{array}$ & $\begin{array}{c}63,341 \\
(19.9 \%) \\
\end{array}$ & $\begin{array}{c}2,761,308 \\
(19.7 \%)\end{array}$ & $\begin{array}{l}111,744 \\
(18.6 \%) \\
\end{array}$ & $\begin{array}{l}141,974 \\
(20.2 \%) \\
\end{array}$ & $\begin{array}{l}187,176 \\
(19.8 \%) \\
\end{array}$ \\
\hline Missing $^{3}$ & $\begin{array}{c}71,014 \\
(14.6 \%) \\
\end{array}$ & $\begin{array}{c}7475 \\
(3.7 \%) \\
\end{array}$ & $\begin{array}{c}2458 \\
(1.0 \%) \\
\end{array}$ & $\begin{array}{c}2764 \\
(0.9 \%) \\
\end{array}$ & $\begin{array}{c}40,261 \\
(0.003 \%) \\
\end{array}$ & $\begin{array}{c}1371 \\
(0.2 \%)\end{array}$ & $\begin{array}{l}2496 \\
(0.4 \%) \\
\end{array}$ & $\begin{array}{c}2543 \\
(0.3 \%) \\
\end{array}$ \\
\hline \multicolumn{9}{|l|}{$\begin{array}{l}\text { Number of patients by } \\
\text { rural/urban status }{ }^{4}(\%)\end{array}$} \\
\hline Rural & $\begin{array}{l}803,136 \\
(16.5 \%)\end{array}$ & $\begin{array}{l}32,303 \\
(16.0 \%)\end{array}$ & $\begin{array}{c}40,565 \\
(16.6 \%)\end{array}$ & $\begin{array}{c}54,185 \\
(17.0 \%)\end{array}$ & $\begin{array}{c}1,806,438 \\
(12.9 \%)\end{array}$ & $\begin{array}{c}87,610 \\
(14.6 \%) \\
\end{array}$ & $\begin{array}{c}91,868 \\
(13.1 \%) \\
\end{array}$ & $\begin{array}{l}110,068 \\
(11.6 \%) \\
\end{array}$ \\
\hline Urban & $\begin{array}{c}3,882,869 \\
(80.0 \%)\end{array}$ & $\begin{array}{l}162,064 \\
(80.4 \%) \\
\end{array}$ & $\begin{array}{l}194,937 \\
(79.8 \%) \\
\end{array}$ & $\begin{array}{l}254,485 \\
(79.8 \%) \\
\end{array}$ & $\begin{array}{c}1,2178,924 \\
(87.0 \%)\end{array}$ & $\begin{array}{l}513,854 \\
(85.4 \%) \\
\end{array}$ & $\begin{array}{l}612,025 \\
(86.9 \%) \\
\end{array}$ & $\begin{array}{l}834,225 \\
(88.1 \%) \\
\end{array}$ \\
\hline Missing & $\begin{array}{l}172,506 \\
(35.5 \%) \\
\end{array}$ & $\begin{array}{c}7243 \\
(3.6 \%)\end{array}$ & $\begin{array}{c}8726 \\
(35.7 \%) \\
\end{array}$ & $\begin{array}{l}10,387 \\
(3.3 \%) \\
\end{array}$ & $\begin{array}{l}12,896 \\
(0.01 \%) \\
\end{array}$ & $\begin{array}{c}295 \\
(0.0 \%) \\
\end{array}$ & $7(0.0 \%)$ & $\begin{array}{c}2206 \\
(0.2 \%) \\
\end{array}$ \\
\hline $\begin{array}{c}\text { Total antibiotic } \\
\text { prescriptions }(N)\end{array}$ & $11,166,401$ & 450,517 & 557,931 & 721,191 & $27,656,014$ & $1,197,646$ & $1,393,583$ & $1,865,267$ \\
\hline $\begin{array}{c}\text { Total indication-associated } \\
\text { prescriptions }(N)\end{array}$ & $10,444,129$ & 409,280 & 508,372 & 645,183 & $13,793,763$ & 622,917 & 682,192 & 934,958 \\
\hline $\begin{array}{l}\text { Total unlinked }{ }^{5} \\
\text { prescriptions }(N)\end{array}$ & 722,272 & 41,237 & 49,559 & 76,008 & $13,862,251$ & 574,729 & 711,391 & 930,309 \\
\hline
\end{tabular}

${ }^{1}$ Population Data BC determined neighborhood income quintile (i.e., household size-adjusted measure of household income) using a postal code-based algorithm standardized by Statistics Canada; ${ }^{2}$ Income quintiles are a relative measure across provinces, lowest $=0-20 \%$ and highest $=81-100 \%$ income bracket; ${ }^{3}$ Missing represents absent or not applicable patient demographic information; ${ }^{4}$ Rural status represents local population of 1000 to 29,999 , urban status represents local population $\geq 30,000 ;{ }^{5}$ Those dispensation records that did not link to physician record within \pm 5 day period; All data presented as whole number (proportion). 
As shown in Figure 1, oral antibiotics were prescribed at an overall, average rate of 768 prescriptions per 1000 population in $\mathrm{ON}$, and 868 prescriptions per 1000 population in BC. Outpatient prescribing for ON seniors decreased by $2.8 \%$ over the study period (785 to 763 prescriptions per 1000 population), and by $7.5 \%$ in BC (854 to 790 prescriptions per 1000 population). In BC, $89 \%$ of all antibiotics dispensed were linked to common infections of interest, while in $\mathrm{ON}, 50 \%$ of antibiotics were associated with common infections in the outpatient setting. Indication-associated prescribing declined by a similar rate in both provinces over the study period (Supplement, Figure S1). In both ON and BC, prescribing for individuals aged $\geq 80$ remained stable by 2018 with less than a $0.5 \%$ increase in both provinces (BC: $0.2 \%, \mathrm{ON}: 0.4 \%$ ), while prescribing for seniors aged $65-79$ years declined (BC: $11 \%, \mathrm{ON}: 5 \%$ ). Additional data on prescribing by class and agent, by age and sex, is available in the online supplement (Supplement, Figures S2-S10).

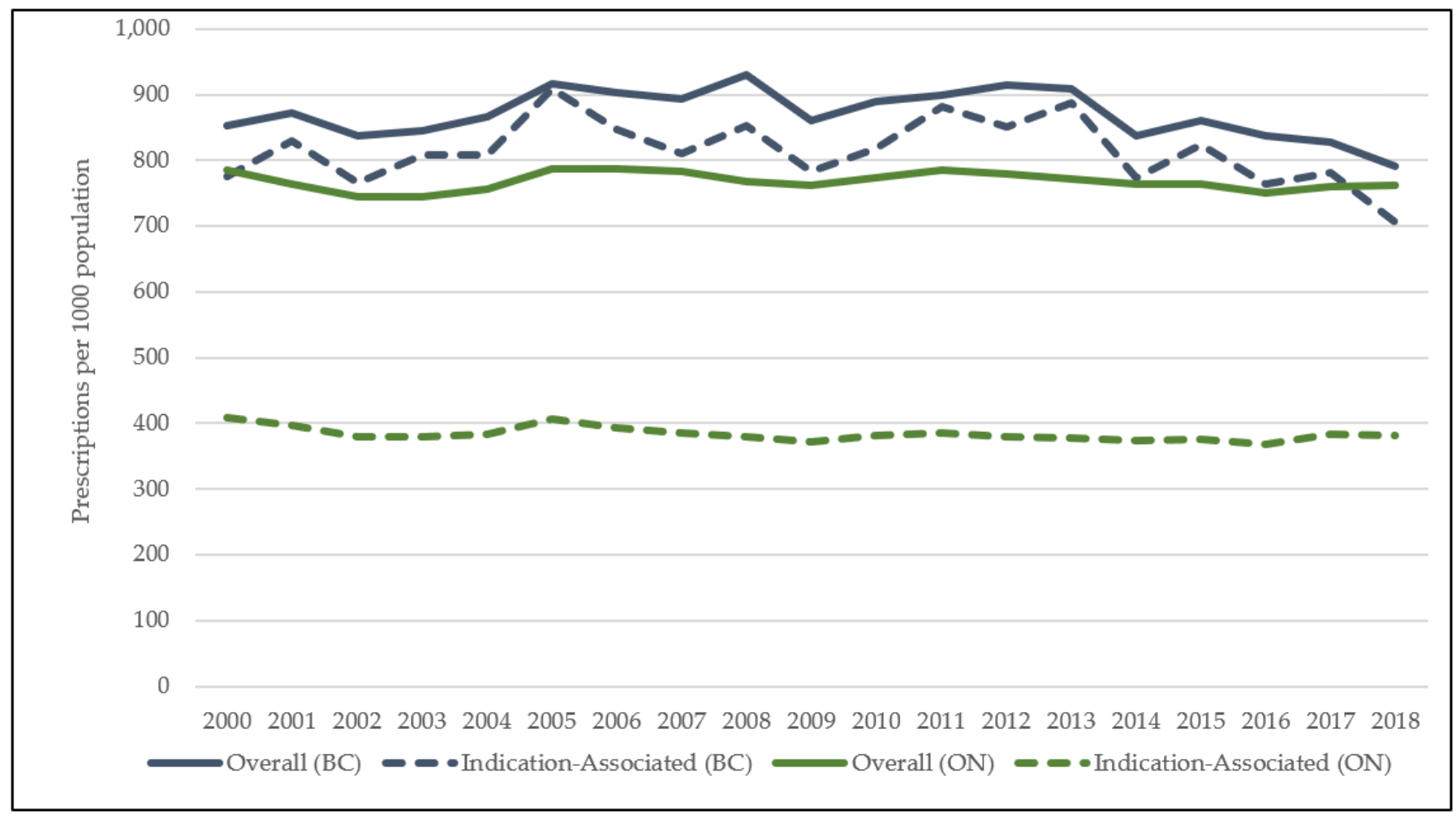

Figure 1. Rate of overall antibiotic use in British Columbia and Ontario, from 2000 to 2018.

Primary Outcome: Indication-Associated Antibiotic Use \& Inappropriate Prescribing

In both provinces, prescribing for Tier 1 diagnoses increased over the study period (BC: $44 \%(\mathrm{r}=0.96 ; p<0.0001) ; \mathrm{ON}: 28 \%(\mathrm{r}=1.00 ; p<0.0001))$ (Table 2). Urinary tract infections (UTI) accounted for most prescriptions within this tier, with 89 prescriptions issued per 1000 in ON, and 129 prescriptions per 1000 in BC, by 2018. Pneumonia-associated prescribing increased by roughly $10 \%$ in both provinces; however, this change was not significant in ON (BC: $11 \%(r=0.93 ; p<0.0001) ; \mathrm{ON}: 7 \%(\mathrm{r}=0.90 ; p=0.053)$. Miscellaneous bacterial infections remained low in magnitude in ON (2018: 3 prescriptions per 1000 population); however, $\mathrm{BC}$ increased over the study period from 2 to 18 prescriptions per 1000 population by $2018(\mathrm{r}=1.00 ; p<0.0001)$. 
Table 2. Rates of antibiotic utilization per 100,000 seniors, by indication, in British Columbia and Ontario.

\begin{tabular}{|c|c|c|c|c|c|c|c|c|c|c|}
\hline \multirow[b]{2}{*}{ Diagnosis Category } & \multicolumn{5}{|c|}{ British Columbia } & \multicolumn{5}{|c|}{ Ontario } \\
\hline & $2000^{1}$ & 2018 & $\begin{array}{l}\text { Percent } \\
\text { Change }^{2}\end{array}$ & $\begin{array}{l}\text { Spearman } \\
\text { Coefficient }\end{array}$ & $p$ Value $^{3}$ & 2000 & 2018 & $\begin{array}{l}\text { Percent } \\
\text { Change }\end{array}$ & $\begin{array}{l}\text { Spearman } \\
\text { Coefficient }\end{array}$ & $p$ Value \\
\hline Tier 1 & 123 & 177 & 44 & 0.96 & $<0.0001$ & 95 & 121 & 27 & 1.00 & $<0.0001$ \\
\hline $\begin{array}{l}\text { Miscellaneous } \\
\text { bacterial }\end{array}$ & 2 & 18 & 800 & 1.00 & $<0.0001$ & 1 & 3 & 200 & 1.00 & $<0.0001$ \\
\hline Pneumonia & 27 & 30 & 11 & 0.93 & $<0.0001$ & 27 & 29 & 7 & 0.9 & 0.053 \\
\hline Urinary tract infection & 94 & 129 & 37 & 0.23 & $<0.0001$ & 67 & 89 & 33 & 0.29 & $<0.0001$ \\
\hline Tier 2 & 93 & 95 & 2 & 0.97 & 0.058 & 64 & 74 & 16 & 1.00 & $<0.0001$ \\
\hline Pharyngitis & 2 & 1 & -50 & -0.51 & $<0.0001$ & 4 & 3 & -25 & 0.95 & 0.76 \\
\hline Sinusitis & 22 & 25 & 14 & 0.96 & $<0.0001$ & 19 & 23 & 21 & 0.99 & $<0.0001$ \\
\hline Otitis media & 6 & 3 & -50 & -0.37 & $<0.0001$ & 3 & 2 & -33 & 0.60 & $<0.0001$ \\
\hline $\begin{array}{l}\text { Skin and soft tissue } \\
\text { infection }\end{array}$ & 58 & 62 & 7 & 0.97 & $<0.0001$ & 37 & 44 & 19 & 0.99 & $<0.0001$ \\
\hline Acne & 1 & 1 & 0 & 0.26 & $<0.0001$ & 1 & 1 & 0 & 0.97 & $<0.0001$ \\
\hline $\begin{array}{l}\text { Gastrointestinal } \\
\text { infections }\end{array}$ & 4 & 4 & 0 & 0.69 & $<0.0001$ & 3 & 3 & 0 & 0.98 & $<0.0001$ \\
\hline Tier 3 & 396 & 306 & -23 & 0.89 & $<0.0001$ & 249 & 187 & -25 & 0.88 & $<0.0001$ \\
\hline Asthma/allergy & 17 & 9 & -47 & 0.29 & $<0.0001$ & 12 & 6 & -50 & -0.31 & $<0.0001$ \\
\hline Bronchitis & 79 & 81 & 3 & 0.95 & $<0.0001$ & 95 & 64 & -33 & 0.52 & $<0.0001$ \\
\hline Influenza & 5 & 3 & -40 & 0.33 & $<0.0001$ & 4 & 2 & -50 & -0.35 & $<0.0001$ \\
\hline Non-suppurative OM & 2 & 1 & -50 & -0.14 & $<0.0001$ & 4 & 3 & -25 & 0.72 & $<0.0001$ \\
\hline Viral URTI & 77 & 34 & -56 & -0.80 & $<0.0001$ & 59 & 37 & -37 & 0.36 & $<0.0001$ \\
\hline Other respiratory tract & 69 & 34 & -51 & -0.67 & $<0.0001$ & 15 & 18 & 20 & 0.98 & $<0.0001$ \\
\hline $\begin{array}{l}\text { Other genitourinary } \\
\text { conditions }\end{array}$ & 87 & 90 & 3 & 0.92 & $<0.0001$ & 25 & 23 & -8 & 0.99 & $<0.0001$ \\
\hline $\begin{array}{l}\text { Other skin, cutaneous } \\
\text { and mucosal } \\
\text { conditions }\end{array}$ & 60 & 53 & -12 & 0.94 & $<0.0001$ & 35 & 33 & -6 & 0.96 & $<0.0001$ \\
\hline $\begin{array}{c}\text { Miscellaneous } \\
\text { non-bacterial }\end{array}$ & 1 & 2 & 100 & 0.92 & $<0.0001$ & 1 & 1 & 0 & 0.99 & $<0.0001$ \\
\hline Unlinked Antibiotics ${ }^{4}$ & 78 & 83 & 6 & 0.38 & $<0.0001$ & 377 & 380 & 1 & 1.00 & $<0.0001$ \\
\hline
\end{tabular}

${ }^{1}$ Rates were calculated as prescriptions per 1000 population using relevant provincial denominators (BC Stats/Intellihealth ON); ${ }^{2}$ Difference in rate of prescribing in 2018 when compared to $2000 ;{ }^{3}$ Refers to the testing for trends from 2000 to $2018 ;{ }^{4}$ Unlinked antibiotics refers to those prescriptions that did not match to a relevant physician billing record within \pm 5 days of dispensation; Abbreviations: OM—otitis media, URTI—upper respiratory tract; Tier I indications always require antibiotics, Tier 2 indications sometimes require antibiotics, Tier 3 rarely/never require antibiotics; Statistics reported included Spearman's rank correlation coefficient and Poisson regression analyses; Double brackets identify non-significant results

Antibiotics were the least prescribed for Tier 2 diagnoses across both provinces (Table 2). By 2018, BC rates for this tier remained stable, while ON saw a $16 \%(r=1.00$; $p<0.0001)$ increase over the study period. Within the diagnoses that sometimes require antibiotics, skin and soft tissue infections (SSTI) and sinusitis were most prescribed. SSTI were prescribed at the highest rates throughout the study period: from 37 to 44 prescriptions per 1000 population in $\mathrm{ON}(\mathrm{r}=0.99 ; p<0.0001)$ and 58 to 62 prescriptions per 1000 population in $\mathrm{BC}(\mathrm{r}=0.97 ; p<0.0001)$. Other diagnoses within this tier included: pharyngitis, otitis media, acne, and gastrointestinal infections (GI), which were all prescribed at $<5$ prescriptions per 1000 population across both provinces.

In any study year, Tier 3 were the most linked diagnoses (Table 2). As these indications do not require antibiotics, as per clinical guidelines, all prescriptions are likely inappropriate. Tier 3 prescribing decreased by $-25 \%$ ( 249 to 189 prescriptions per 1000 population $(\mathrm{r}=0.88 ; p<0.0001))$ in $\mathrm{ON}$, and $-23 \%$ in BC (396 to 306 prescriptions per 1000 population $(\mathrm{r}=0.89 ; p<0.0001))$. Across both provinces, inappropriate prescribing for respiratory 
infections led within this tier. However, while prescribing for bronchitis decreased by $-33 \%(\mathrm{r}=0.52 ; p<0.0001)$ in $\mathrm{ON}$, a $3 \%(\mathrm{r}=0.95 ; p<0.0001)$ increase was observed in $\mathrm{BC}$ by 2018. Viral upper respiratory tract infections (URTI) decreased across both provinces, by $-38 \%(\mathrm{r}=0.036 ; p<0.0001)$ and $-56 \%(\mathrm{r}=-0.80 ; p<0.0001)$ in $\mathrm{ON}$ and $\mathrm{BC}$, respectively. Other Tier 3 indications followed similar directional trends across provinces, with varying magnitudes, except for other genitourinary tract infections. This indication declined in ON by $-8 \%(\mathrm{r}=0.99 ; p<0.0001)$, with a $3 \%(\mathrm{r}=0.92 ; p<0.0001)$ increase in $\mathrm{BC}$.

The antibiotic classes prescribed for common infections varied over the study period; however, similarities were identified across provinces (Table 3). Decreasing trends were observed for the classes of sulfonamides and trimethoprim (ON: $-46 \%(\mathrm{r}=-0.28 ; p<0.0001)$; BC: $-37 \%(\mathrm{r}=0.97 ; p<0.0001))$, macrolides $(\mathrm{ON}:-30 \%(\mathrm{r}=0.48 ; p<0.0001) ; \mathrm{BC}:-44 \%$ $(\mathrm{r}=-0.28 ; p<0.0001))$, and quinolones $(\mathrm{ON}:-31 \%(\mathrm{r}=0.59 ; p<0.0001) ; \mathrm{BC}:-29 \%$ $(\mathrm{r}=0.36 ; p<0.0001))$. The decrease in macrolides was related to a drop in erythromycin prescribing between 2000 and 2008 and a drop in clarithromycin use in the last decade. Beta-lactam penicillin (ON: 13\% ( $\mathrm{r}=0.61 ; p<0.0001)$; BC: $7 \%(\mathrm{r}=0.75 ; p<0.0001)$ ) use increased marginally in comparison to the more marked increase in the class of tetracyclines (ON: $45 \%(\mathrm{r}=-0.48 ; p<0.0001)$; BC: $103 \%(\mathrm{r}=0.91 ; p<0.0001))$ The only class that diverged in directional trend over the study period was other beta lactam antibiotics (i.e., cephalosporins), with a slight increase in $\mathrm{ON}(2 \%(\mathrm{r}=0.94 ; p<0.0001))$ but a decrease in BC $(-13 \%(r=0.75 ; p<0.0001))$. The largest increase for both provinces was identified in other antibacterials (ON: 239\% ( $\mathrm{r}=1.00 ; p<0.0001)$; BC: $109 \%(\mathrm{r}=0.97 ; p<0.0001))$, with nitrofurantoin being the primary antibiotic accounting for this.

Table 3. Utilization by major class for indication-associated antibiotics prescriptions in British Columbia and Ontario.

\begin{tabular}{|c|c|c|c|c|c|c|c|c|c|c|}
\hline \multirow{2}{*}{ Antibiotic (ATC Class) } & \multicolumn{5}{|c|}{ British Columbia } & \multicolumn{5}{|c|}{ Ontario } \\
\hline & $2000^{1}$ & 2018 & $\begin{array}{l}\text { Percent } \\
\text { Change }^{2}\end{array}$ & $\begin{array}{l}\text { Spearman } \\
\text { Coefficient }\end{array}$ & $p$ Value $^{3}$ & 2000 & 2018 & $\begin{array}{l}\text { Percent } \\
\text { Change }\end{array}$ & $\begin{array}{l}\text { Spearman } \\
\text { Coefficient }\end{array}$ & $p$ Value \\
\hline Overall (J01) & 775 & 707 & -9 & 0.95 & $<0.0001$ & 408 & 382 & -6 & 0.97 & $<0.0001$ \\
\hline Tetracyclines (J01A) & 33 & 67 & 103 & 0.91 & $<0.0001$ & 5 & 7 & 40 & -0.48 & $<0.0001$ \\
\hline $\begin{array}{l}\text { Beta-Lactam Penicillins } \\
\text { (J01C) }\end{array}$ & 129 & 138 & 7 & 0.75 & $<0.0001$ & 82 & 93 & 13 & 0.61 & $<0.0001$ \\
\hline $\begin{array}{l}\text { Other Beta-Lactams } \\
\text { (J01D) }\end{array}$ & 153 & 134 & -13 & 0.94 & $<0.0001$ & 69 & 70 & 1 & 0.94 & $<0.0001$ \\
\hline $\begin{array}{c}\text { Sulfonamides \& } \\
\text { Trimethoprim (J01E) }\end{array}$ & 71 & 45 & -37 & 0.97 & $<0.0001$ & 32 & 17 & -47 & -0.28 & $<0.0001$ \\
\hline $\begin{array}{c}\text { Macrolides, } \\
\text { Lincosamides and } \\
\text { Streptogramins (J01F) }\end{array}$ & 148 & 82 & -44 & -0.28 & $<0.0001$ & 105 & 74 & -30 & 0.48 & $<0.0001$ \\
\hline Quinolones (J01M) & 192 & 136 & -29 & 0.36 & $<0.0001$ & 101 & 69 & -32 & 0.59 & $<0.0001$ \\
\hline $\begin{array}{l}\text { Other Antibacterials } \\
\text { (J01X) }\end{array}$ & 50 & 105 & 109 & 0.97 & $<0.0001$ & 15 & 52 & 247 & 1.00 & $<0.0001$ \\
\hline
\end{tabular}

${ }^{1}$ Rates were calculated as prescriptions per 1000 population using relevant provincial denominators (BC Stats/Intellihealth ON);

2 Difference in rate of prescribing in 2018 when compared to $2000 ;{ }^{3}$ Refers to the testing for trends from 2000 to 2018; Abbreviations:

ATC—anatomical therapeutic chemical, OM—otitis media, URTI—upper respiratory tract; Statistics reported included Spearman's rank correlation coefficient and Poisson regression analyses.

\section{Discussion}

This is the first study in Canada to evaluate primary care antibiotic appropriateness across two large provinces. Across Ontario and BC, indications for which antibiotics are not required were the most heavily prescribed for seniors-In any study year, followed by antibiotic prescribing for Tier 1 where antibiotics are always required. Both provinces were similar in the agents prescribed for indications apart from tetracyclines-wherein BC prescribing eclipsed Ontario and overall prescribing for doxycycline in $\mathrm{BC}$ was six times more than in Ontario. 
With respect to prescribing quality, Canadian seniors continue to be overprescribed antibiotics for conditions that do not warrant their use [14,23]. Despite the fact that antibiotic use is unnecessary, Tier 3 indications were prescribed at rates 2-4 times higher than other tiers. In both provinces, bronchitis received high levels of antibiotic prescription; however, while BC prescribing remained stable for this indication, Ontario saw a $30 \%$ reduction in antibiotic use. Although Tier 3 indications remained the most prescribed-for diagnoses throughout the study period, a declining trend over time is encouraging, with much room for improvement remaining. Robust and ongoing elevated prescribing for Tier 3 indications has been corroborated across multiple studies and geographic regions [11,24-27]. Despite the inefficacy of antibiotics for non-bacterial conditions, prescriptions issued for these diagnoses continue to dominate. In the US, 30\% of outpatient prescribing is inappropriate; moreover, these rates have not significantly improved for adult populations since their initial reporting in 2016 [24,25]. In the United Kingdom, at least 20\% of all antibiotics are used inappropriately in the outpatient setting $[28,29]$. Our study identified $49 \%$ of all indication-associated prescriptions in Ontario, and 53\% in BC were dispensed inappropriately to Canadian seniors. A previous study examining a relatively small and select group of Canadian practitioners reported only $13 \%$ of prescriptions issued to seniors in Ontario were inappropriate [14]. The population wide sampling of our study provides a more accurate view of overall practices, and our methodology (i.e., diagnostic classification into Tiers 1, 2 and 3) aligns with previous published data from the United States and offers a more direct comparison with reported results, dissuading the notion that Canadian seniors receive less inappropriate or unnecessary prescriptions.

In comparing the most common agents used, Ontario has adopted increased use of penicillins over time, driven by the use of amoxicillin. This shift to the use of betalactams is accompanied by the decreased use of macrolides, erythromycin in the early days and, more recently, clarithromycin, quinolones, mostly related to ciprofloxacin, and sulfonamides/trimethoprim classes. Despite the aggregate stability in prescribing, the shifting landscape of common agents highlight trends of optimization, in the absence of reduced quantity. A decline in use for the same three classes is also reflected in BC; however, a complimentary increase has been observed in tetracycline antibiotics-prescribed at rates four times that of $\mathrm{ON}$. One reason for this difference in magnitude may be doxycycline first entering the BC formulary in 2002, but only covered by the Ontario Drug Benefit Program (ODB) as of 2009 [30,31]. Additionally, we speculate that the suspected switch to the use of doxycycline for respiratory infections in BC may explain the interprovincial gap, where beta-lactams are the preferred agents in Ontario. Another reason for the disparity in tetracycline use might be the varying population demographics across provinces-with BC's population older, on average [32]. Trends in antibiotic use for both provinces, across various patient demographics were comparable-with females aged 65-79 years, in urban settings and lower income quintiles being more likely to be prescribed (Supplement, Table S3). However, a difference in prescribing culture may also be culpable as Bugs and Drugs, the leading clinical practice guideline in BC, emphasizes tetracycline use more so than other comparable resources [33]. By contrast, Health Quality Ontario promotes the use of beta-lactam monotherapy, especially for cases of community-acquired pneumonia. The divergence in clinical guidelines and prescribing practice highlight a stark difference across two otherwise comparable healthcare systems. Provincial antibiograms and/or patient demographics might account for this difference in antibiotic use; however, this provincial variability is likely multifactorial, and not clearly elucidated.

Although optimization of drug choice, with narrowest spectrum and shortest duration being a central tenant of antimicrobial stewardship, this study highlights the reduction of unnecessary prescribing as an ongoing, high priority issue for Canadian seniors. Elevated antimicrobial use in Canadian seniors is especially concerning in the wake of prolonged antimicrobial stewardship (AMS) efforts. Formal evaluation of AMS impact was beyond the scope of this study; however, both provinces have endeavored to curb the unnecessary use of antibiotics. In BC, the Do Bugs Need Drugs campaign has been operating since 2005, 
offering accredited courses on appropriate antibiotic use, disseminating guidelines and physician resources [34]. By contrast, Public Health Ontario promotes the principles of AMS, put forth through federal initiatives and further adopted by the Choosing Wisely initiative in 2016 [35,36]. These initiatives promote conversations between clinicians and patients regarding unnecessary antibiotic use. Although some improvements in the trends of antibiotic classes used were identified in this study, there remains a high level of inappropriate prescribing in both provinces. In BC, AMS efforts have been attributed to an overall decline in antibiotic use; however, this trend is driven by younger populations with much work to be done in seniors [23].

This study has limitations inherent to all retrospective studies using administrative health data. Physician billing records were used to extract indication data to characterize antibiotic prescriptions. In BC, $89 \%$ of all prescriptions were linked to a physician record for a common infection, with only $50 \%$ of Ontario prescriptions linked. These rates were expected cross-provincially and demonstrate an improvement in linkage, in comparison to previous studies of Canadian outpatient care [37]. The unlinked prescriptions in Ontario could be evenly attributed to diagnoses beyond the scope of this study or no record. The latter are likely attributable to hospital and/or emergency department visits, with subsequent prescriptions dispensed in the community, not included within study scope. Although it is notable that Canadian primary-care physician claims data has a high positive-predictive value for diagnosis of common infections, including acute non-bacterial upper-respiratory infections $(0.84,95 \%$ CI: 0.81 to 0.88$)$, differences in coding practices across provinces are not unknown [38]. In BC, the inflated use of certain Tier 3 codes (e.g., other-genitourinary-conditions) may signify an underlying systematic difference in provincial coding practices. Often utilized by prescribers for patient presentations that do not fulfill more specific diagnosis criterium (e.g., cystitis), elevated use of these codes raises alarms regarding prescribing or coding quality. These "other" diagnoses also exist for skin/soft tissue and respiratory tract infections. By 2018, prescribing for "other respiratory tract" infections halved in BC, although it was still twice the Ontario rate. The difference in scale for these indications, across otherwise comparable landscapes of primary care, compels further investigation into BC administrative data. Despite its routine utilization for research purposes, no previous studies validating $\mathrm{BC}$ administrative health data, for relevant ICD -9 codes, were identified by the authors. Furthermore, as the nature of our data prevents nested analyses, multiple prescriptions were permitted per individual, and our standard error may be biased. Rates do not account for unfilled prescriptions, and levels of compliance to medications are unknown. In the absence of lab data to confirm bacterial infection, or patient comorbidity data, our use of billing codes may be subject to misclassification bias. Finally, our study focused exclusively on patients aged $>65$. Substantial improvements in antibiotic prescribing in paediatrics have occurred, but assessments in other age groups are needed.

\section{Materials and Methods}

\subsection{Data Sources}

The BC Ministry of Health and ICES (formerly known as the Institute for Clinical Evaluative Sciences) in Ontario house several health care-related databases, which have comprehensive information on their populations. Antibiotic information was extracted from the BC PharmaNet, and Ontario Drug Benefit (ODB) program systems [30,39]. The Medical Service Plan (MSP) billing system and the Ontario Health Insurance Plan (OHIP) record all claims submitted by physicians for services provided to residents of $\mathrm{BC}$ and Ontario, respectively, including diagnostic codes [40]. BC data were extracted, anonymized, and made available to researchers by Population Data BC. Ontario datasets were linked using unique encoded identifiers and analyzed at ICES. These provincial databases have been used repeatably to evaluate antimicrobial use at the population-level $[37,38]$. 


\subsection{Study Population}

All residents of $B C$ and $O N$ aged $\geq 65(<105)$ years, with a valid provincial health care number, from 1 January 2000 to 31 December 2018 were included. Antibiotic data, limited to oral use only (continuous $<30$-day supply) were matched to physician billing records using anonymized patient identifiers. Indication data were pulled from physician billing records in the outpatient setting [41,42]. Prescriptions were matched to a practitioner service date within a 5-day range. A three-tiered hierarchy was applied to link only the most relevant diagnostic code to the prescription (Supplement, Table S1) [24]. This hierarchy has been utilized in several studies, and it includes: Tier 1 indications (always require antibiotic prescription); Tier 2 (sometimes requiring); and Tier 3 (antibiotics unnecessary) $[14,25,26,43]$. If multiple codes were present within a given linkage period, then precedent was given to Tier 1. Prescriptions that did not match to any physician record were classified as unlinked, while those that matched to an indication beyond study scope were flagged as other diagnosis.

\subsection{Outcomes \& Statistical Analyses}

Diagnostic codes were based on the ninth revision of the International Classification of Diseases developed by WHO, commonly referred to as ICD-9. Several codes were grouped within diagnostic categories and subsequent hierarchy tiers. Tier 1 includes: miscellaneous bacterial infections, pneumonia, and urinary tract infections. Tier 2 includes: acne, gastrointestinal infections, otitis media, pharyngitis, sinusitis, and skin and soft tissue infections. Tier 3 includes: asthma/allergy, bronchitis/bronchiolitis, influenza, miscellaneous bacterial infections, non-suppurative otitis media, other genitourinary conditions, other respiratory tract conditions, other skin, cutaneous and mucosal conditions, and viral upper respiratory tract infections. (Supplement, Table S1). Antibiotics were classified based on the Anatomical Therapeutic Chemical (ATC) classification system [44]. Seven major J01, antibiotic classes were included: tetracyclines (J01A); beta-lactams (J01C); other beta-lactams (J01D); sulfonamides and trimethoprim (J01E); macrolides, lincosamides and streptogramins (J01F); quinolones (J01M); and other antibacterials (J01X) (Supplement, Table S2).

Cohort demographics were first examined by age, sex and income quintiles as well as urban/rural status. Consumption rates were calculated as the number of prescriptions per 1000 population per year, using age- and gender-specific denominators for each province $[32,45,46]$. The primary study outcome was rate of prescribing for common infections, defined as: indication-associated antibiotic prescribing. Indication-associated prescribing was further stratified by a 3-tiered hierarchy to further characterize prescribing quality: Tier 1 (always required), Tier 2 (sometimes required) and Tier 3 (never required). Temporal trends in antibiotic use were evaluated using both the Spearman correlation coefficient and Poisson regression, where a two-sided $p$-value $<0.05$ was considered significant. Baseline rates of antibiotic use were also examined for the cohort, by major ATC class, clinically relevant drugs and patient age and sex. All outcomes of interest with $n<6$ were excluded from subsequent analyses to preserve subject anonymity. In both provinces, analyses were conducted using SAS version 9.4 (SAS Institute, Cary, NC, USA), with the addition of $\mathrm{R}$ version 4.0.2 in BC.

\section{Conclusions}

This is the first study in Canada to evaluate primary care antibiotic appropriateness across two large provinces. Across Ontario and British Columbia, indications for which antibiotics are not required were the most heavily prescribed for seniors-in any study year, followed by antibiotic prescribing for Tier 1 where antibiotics are always required. Although antibiotic use remains high, our study identified some positive changes in prescribing patterns for Canadian seniors, with optimizations in drug choice and reductions in prescribing for Tier 3 indications (i.e., never require antibiotics), over time. However, prescribing quality remains an issue of high concern, with approximately $50 \%$ of antibi- 
otics, across two Canadian provinces, used inappropriately. Research to further delineate prescribing quality by dose, duration, and lab susceptibility is underway in both provinces.

Supplementary Materials: The following are available online at https:/ /www.mdpi.com/article/ 10.3390/antibiotics10121484/s1, Table S1: diagnostic hierarchy, Table S2: antibiotics within anatomical therapeutic class, Table S3: cohort characteristics, Table S4: overall rate of antibiotic use by indication tier, and diagnosis, Table S5: rate of indication-associated antibiotic use by major ATC class, Figure S1: antibiotic prescriptions by age category, Figure S2: rate of overall antibiotic (J01) use by sex, Figure S3: antibiotic prescriptions by major ATC classification, Figure S4: tetracycline (J01A) antibiotic use, Figure S5: penicillin (J01C) antibiotic use, Figure S6: other beta-lactam (J01D) antibiotic use, Figure S7: sulfamethoxazole and trimethoprim (J01E) antibiotic use, Figure S8: macrolide, lincosamide and streptogramin (J01F) antibiotic use, Figure S9: quinolone (J01M) antibiotic use, Figure S10: other antibacterials (J01X) antibiotic use.

Author Contributions: All authors, led by F.M., conceptualized the study, which was funded by a 2018 CIHR Project Grant. A.S. conducted the literature review; conducted BC data cleaning, analysis and interpretation and, under the guidance of F.M., composed the initial draft; A.S., S.Z.S. and J.N.R. drafted the antibiotic case capture code and reviewed the manuscript; M.S., A.M.M., M.P. and D.M.P. provided critical physician interpretation as well as study methodology. R.C.R. provided BC lab data and reviewed the manuscript. All authors have read and agreed to the published version of the manuscript.

Funding: This work was supported by a Canadian Institutes of Health Research (CIHR) project grant (201809-408648). CIHR is the major federal agency responsible for funding health and medical research in Canada.

Institutional Review Board Statement: The study was approved by the Behavourial Research Ethics Board of the University of British Columbia (H19-00799).

Informed Consent Statement: Not applicable.

Data Availability Statement: Restrictions apply to the availability of these data.

Acknowledgments: This study was supported by ICES, which is funded by an annual grant from the Ontario Ministry of Health (MOH) and the Ministry of Long-Term Care (MLTC). The study was completed at the ICES Western site, where core funding is provided by the Academic Medical Organization of Southwestern Ontario, the Schulich School of Medicine and Dentistry, Western University and the Lawson Health Research Institute. Parts of this material are based on data and/or information compiled and provided by Ontario MOH, MLTC and CIHI. However, the analyses, conclusions, opinions and statements expressed in the material are those of the author(s), and not necessarily those of MOH, MLTC and CIHI. We thank IQVIA Solutions Canada Inc. for the use of their Drug Information File. All inferences, opinions and conclusions drawn in this study are those of the authors and do not reflect the opinions or policies of the BC Data Steward(s). The use of Ontario data in this project is authorized under section 45 of Ontario's Personal Health Information Protection Act (PHIPA) and does not require review by a Research Ethics Board. The use of BC data was provided through Population Data BC and required review by UBC Ethics.

Conflicts of Interest: The authors declare no conflict of interest. The funders had no role in the design of the study; in the collection, analyses, or interpretation of data; in the writing of the manuscript or in the decision to publish the results.

\section{References}

1. World Health Organization. Global Action Plan on Antimicrobial Resistance. 2015. Available online: https://apps.who.int/iris/ handle/10665/193736 (accessed on 14 September 2020).

2. Atlanta: Division of Healthcare Quality Promotion, National Center for Emerging and Zoonotic Infectious Disease, Centers for Disease Control and Prevention. National Action Plan for Combating Antibiotic-Resistant Bacteria. 2015. Available online: www.cdc.gov/drugresistance/pdf/national_action_plan_for_combating_antibotic-resistant_bacteria.pdf (accessed on 20 October 2021).

3. Contained and Controlled: The UK's 20-Year Vision for Antimicrobial Resistance. London (UK): HM Government. 2019. Available online: https://assets.publishing.service.gov.uk/government/uploads/system/uploads/attachment_data/file/773065/uk20-year-vision-for-antimicrobial-resistance.pdf (accessed on 20 October 2021). 
4. Tackling Antimicrobial Resistance 2019-2024: The UK's Five-Year National Action Plan. London (UK): HM Government. 2019. Available online: https:/ / assets.publishing.service.gov.uk/government/uploads/system/uploads/attachment_data/file/78 4894/UK_AMR_5_year_national_action_plan.pdf (accessed on 19 October 2021).

5. Australia's National Antimicrobial Resistance Strategy-2020 and beyond. Antimicrobial Resistance. Published 10 March 2020. Available online: https:/ / www.amr.gov.au/resources/australias-national-antimicrobial-resistance-strategy-2020-and-beyond (accessed on 22 October 2021).

6. Van Katwyk, S.R.; Grimshaw, J.M.; Hoffman, S.J. Ten Years of Inaction on Antimicrobial Resistance: An Environmental Scan of Policies in Canada from 2008 to 2018. Healthc. Policy 2020, 15, 48-62. [CrossRef]

7. Public Health Agency of Canada. Handling Antibiotics with Care: Preserving Antibiotics Now and in the Future: Spotlight Report 2019. Published 20 September 2019. Available online: https://www.canada.ca/en/public-health/corporate/publications/ chief-public-health-officer-reports-state-public-health-canada/preserving-antibiotics/handling-antibiotics.html (accessed on 4 June 2020).

8. Public Health Agency of Canada. Canadian Antimicrobial Resistance Surveillance System-Update 2020. aem. Published 9 July 2020. Available online: https://www.canada.ca/en/public-health/services/publications/drugs-health-products/canadianantimicrobial-resistance-surveillance-system-2020-report.html (accessed on 5 August 2021).

9. Public Health Agency of Canada. Canadian Antimicrobial Resistance Surveillance System 2017 Report-Executive Summary. aem. Published 10 November 2017. Available online: https://www.canada.ca/en/public-health/services/publications/ drugs-health-products / canadian-antimicrobial-resistance-surveillance-system-2017-report-executive-summary.html (accessed on 17 January 2021).

10. Silverman, M.; Povitz, M.; Sontrop, J.M.; Li, L.; Richard, L.; Cejic, S.; Shariff, S. Antibiotic Prescribing for Nonbacterial Acute Upper Respiratory Infections in Elderly Persons. Ann. Intern. Med. 2017, 166, 765-774. [CrossRef] [PubMed]

11. Tan, C.; Graves, E.; Lu, H.; Chen, A.; Li, S.; Schwartz, K.L.; Daneman, N. A decade of outpatient antimicrobial use in older adults in Ontario: A descriptive study. CMAJ Open 2017, 5, E878-E885. [CrossRef] [PubMed]

12. Jain, S.; Self, W.H.; Wunderink, R.G.; Fakhran, S.; Balk, R.; Bramley, A.M.; Reed, C.; Grijalva, C.G.; Anderson, E.J.; Courtney, D.M.; et al. Community-Acquired Pneumonia Requiring Hospitalization among US Adults. N. Engl. J. Med. 2015, 373, 415-427. [CrossRef]

13. Chen, H.; Hara, Y.; Horita, N.; Saigusa, Y.; Hirai, Y.; Kaneko, T. Declined Functional Status Prolonged Hospital Stay for Community-Acquired Pneumonia in Seniors. Clin. Interv. Aging 2020, 15, 1513-1519. [CrossRef]

14. Schwartz, K.L.; Langford, B.J.; Daneman, N.; Chen, B.; Brown, K.A.; McIsaac, W.; Tu, K.; Candido, E.; Johnstone, J.; Leung, V.; et al. Unnecessary antibiotic prescribing in a Canadian primary care setting: A descriptive analysis using routinely collected electronic medical record data. CMAJ Open 2020, 8, E360-E369. [CrossRef]

15. Gulliford, M.C.; Prevost, T.; Charlton, J.; Juszczyk, D.; Soames, J.; McDermott, L.; Sultana, K.; Wright, M.; Fox, R.; Hay, A.; et al. Effectiveness and safety of electronically delivered prescribing feedback and decision support on antibiotic use for respiratory illness in primary care: REDUCE cluster randomised trial. BMJ 2019, 364, 1236. [CrossRef] [PubMed]

16. Brown, K.A.; Langford, B.; Schwartz, K.L.; Diong, C.; Garber, G.; Daneman, N. Antibiotic Prescribing Choices and Their Comparative C. Difficile Infection Risks: A Longitudinal Case-Cohort Study. Clin. Infect. Dis. 2021, 72, 836-844. [CrossRef]

17. Saha, S.; Kapoor, S.; Tariq, R.; Schuetz, A.N.; Tosh, P.K.; Pardi, D.S.; Khanna, S. Increasing antibiotic resistance in Clostridioides difficile: A systematic review and meta-analysis. Anaerobe 2019, 58, 35-46. [CrossRef]

18. So, A.D.; Shah, T.A.; Roach, S.; Chee, Y.L.; Nachman, K.E. An Integrated Systems Approach is Needed to Ensure the Sustainability of Antibiotic Effectiveness for Both Humans and Animals. J. Law Med. Ethics 2015, 43, 38-45. [CrossRef]

19. Laxminarayan, R.; Duse, A.; Wattal, C.; Zaidi, A.K.M.; Wertheim, H.F.L.; Sumpradit, N.; Vlieghe, E.; Hara, G.L.; Gould, I.M.; Goossens, H.; et al. Antibiotic resistance-the need for global solutions. Lancet Infect. Dis. 2013, 13, 1057-1098. [CrossRef]

20. Aarestrup, F.M.; Wegener, H.C.; Collignon, P. Resistance in bacteria of the food chain: Epidemiology and control strategies. Expert Rev. Anti-Infect. Ther. 2008, 6, 733-750. [CrossRef] [PubMed]

21. O'Neill, J. Tackling Drug-Resistant Infections Globally: Final Report and Recommendations. Government of the United King-dom. 2016. Available online: https:/ / apo.org.au/node/63983 (accessed on 27 October 2021).

22. Spivak, E.S.; Cosgrove, S.E.; Srinivasan, A. Measuring Appropriate Antimicrobial Use: Attempts at Opening the Black Box. Clin. Infect. Dis. 2016, 63, 1-6. [CrossRef]

23. McKay, R.M.; Vrbova, L.; Fuertes, E.; Chong, M.; David, S.; Dreher, K.; Purych, D.; Blondel-Hill, E.; Henry, B.; Marra, F.; et al. Evaluation of the Do Bugs Need Drugs? Program in British Columbia: Can we curb antibiotic prescribing? Can. J. Infect. Dis. Med. Microbiol. 2011, 22, 19-24. [CrossRef]

24. Fleming-Dutra, K.E.; Hersh, A.L.; Shapiro, D.J.; Bartoces, M.; Enns, E.A.; File, T.M., Jr.; Finkelstein, J.A.; Gerber, J.S.; Hyun, D.Y.; Linder, J.A.; et al. Prevalence of Inappropriate Antibiotic Prescriptions Among US Ambulatory Care Visits, 2010-2011. JAMA 2016, 315, 1864-1873. [CrossRef] [PubMed]

25. Hersh, A.L.; King, L.M.; Shapiro, D.J.; Hicks, L.A.; Fleming-Dutra, K.E. Unnecessary Antibiotic Prescribing in US Ambulatory Care Settings, 2010-2015. Clin. Infect. Dis. 2021, 72, 133-137. [CrossRef]

26. Chua, K.-P.; Fischer, M.A.; Linder, J.A. Appropriateness of outpatient antibiotic prescribing among privately insured US patients: ICD-10-CM based cross sectional study. BMJ 2019, 364, k5092. [CrossRef] 
27. Dolk, F.C.K.; Pouwels, K.B.; Smith, D.R.M.; Robotham, J.V.; Smieszek, T. Antibiotics in primary care in England: Which antibiotics are prescribed and for which conditions? J. Antimicrob. Chemother. 2018, 73 (Suppl. 2), ii2-ii10. [CrossRef]

28. Smieszek, T.; Pouwels, K.B.; Dolk, F.C.K.; Smith, D.; Hopkins, S.; Sharland, M.; Hay, A.; Moore, M.; Robotham, J.V. Potential for reducing inappropriate antibiotic prescribing in English primary care. J. Antimicrob. Chemother. 2018, 73 (Suppl. 2), ii36-ii43. [CrossRef] [PubMed]

29. Pouwels, K.B.; Dolk, F.C.K.; Smith, D.R.M.; Robotham, J.V.; Smieszek, T. Actual versus 'ideal' antibiotic prescribing for common conditions in English primary care. J. Antimicrob. Chemother. 2018, 73 (Suppl. 2), 19-26. [CrossRef]

30. Ontario, C.A. Get Coverage for Prescription Drugs. Available online: http:/ / www.ontario.ca/page/get-coverage-prescriptiondrugs (accessed on 1 December 2021).

31. PharmaCare Drug Review Results. Available online: https://fmdb.hlth.gov.bc.ca/ (accessed on 28 September 2021).

32. Government of Canada Statistics Canada. Population Estimates, Quarterly. Published 18 March 2021. Available online: https:/ / www150.statcan.gc.ca/t1/tbl1/en/tv.action?pid=1710000901 (accessed on 17 May 2021).

33. Blondel-Hill, E.; Fryters, S. Bugs \& Drugs: An Antimicrobial/Infectious Diseases Reference; Alberta Health Services: Edmonton, AB, Canada, 2012.

34. Healthcare Professionals. Do Bugs Need Drugs? Available online: http:/ / www.dobugsneeddrugs.org/health-care-professionals/ (accessed on 1 December 2021).

35. Antimicrobial Awareness Week Canada. Available online: https://antibioticawareness.ca/ (accessed on 2 October 2021).

36. Born, K.B.; Leis, J.A.; Gold, W.L.; Levinson, W. “Choosing Wisely Canada” and antimicrobial stewardship: A shared focus on reducing unnecessary care. Can. Commun. Dis. Rep. 2015, 41 (Suppl. 4), 9-13. [CrossRef] [PubMed]

37. Levy, A.R.; O’Brien, B.J.; Sellors, C.; Grootendorst, P.; Willison, N. Coding accuracy of administrative drug claims in the Ontario Drug Benefit database. Can. J. Clin. Pharmacol. J. Can. Pharmacol. Clin. 2003, 10, 67-71.

38. Cadieux, G.; Tamblyn, R. Accuracy of Physician Billing Claims for Identifying Acute Respiratory Infections in Primary Care. Health Serv. Res. 2008, 43, 2223-2238. [CrossRef] [PubMed]

39. BC Ministry of Health [Creator]. PharmaNet. V2. BC Ministry of Health [Publisher]. Data Extract. Data Stewardship Committee. 2011. Available online: http:/ / www.popdata.bc.ca/data (accessed on 1 December 2021).

40. British Columbia Ministry of Health [creator]. Medical Services Plan (MSP) Payment Information File. V2. Population Data BC [publisher]. Data Extract. MOH. 2011. Available online: http://www.popdata.bc.ca/data (accessed on 1 December 2021).

41. British Columbia Ministry of Health. Diagnostic Code Descriptions (ICD-9)-Province of British Columbia. Available online: https://www2.gov.bc.ca/gov/content/health/practitioner-professional-resources/msp/physicians/diagnostic-codedescriptions-icd-9 (accessed on 1 December 2021).

42. ICD-9 International Classification of Diseases, Ninth Revision. Published 1 March 2019. Available online: https://www.cdc.gov / nchs/icd/icd9.htm (accessed on 3 November 2020).

43. Saatchi, A.; Morris, A.M.; Patrick, D.M.; Mccormack, J.; Reyes, R.C.; Morehouse, P.; Reid, J.; Shariff, S.; Povitz, M.; Silverman, M.; et al. Outpatient antibiotic use in British Columbia, Canada: Reviewing major trends since 2000. JAC-Antimicrobial. Resist. 2021, 3, dlab116. [CrossRef] [PubMed]

44. WHO Collaborating Centre for Drug Statistics Methodology, Folkehelseinstituttet (Noruega). Guidelines for ATC Classification and DDD Assignment 2011. WHO Collaborating Centre for Drug Statistics Methodology: Norwegian Institute of Public Health. 2010. Available online: http:/ / www.whocc.no/filearchive/publications/2011guidelines.pdf (accessed on 15 April 2020).

45. IntelliHealth Ontario. Available online: https:/ /intellihealth.moh.gov.on.ca (accessed on 28 September 2021).

46. British Columbia Ministry of Health [creator]. Consolidation File (MSP Registration \& Premium Billing). V2. Population Data BC [publisher]. Data Extract. MOH. 2011. Available online: http://www.popdata.bc.ca/data (accessed on 1 December 2021). 